\title{
Cytotoxic effects of two acid solutions and $2.5 \%$ sodium hypochlorite used in endodontic therapy
}

\author{
Esther Navarro-Escobar ${ }^{1}$, María-Paloma González-Rodríguez ${ }^{2}$, Carmen-María Ferrer-Luque ${ }^{3}$
}

\begin{abstract}
${ }^{1}$ BDS, Graduate in Dentistry. Department of Dental Pathology and Therapeutics, School of Dentistry, University of Granada ${ }^{2}$ DDS, PhD, Contracted Profesor. Department of Dental Pathology and Therapeutics, School of Dentistry, University of Granada ${ }^{3}$ DDS, MD, PhD, Associate Professor. Department of Dental Pathology and Therapeutics, School of Dentistry, University of Granada (Spain)
\end{abstract}

Correspondence:

Department of Dental Pathology and Therapeutics School of Dentistry, University of Granada, Spain Campus de Cartuja, Colegio Maximo s $/ n$. 18071, Granada, Spain cferrer@ugr.es

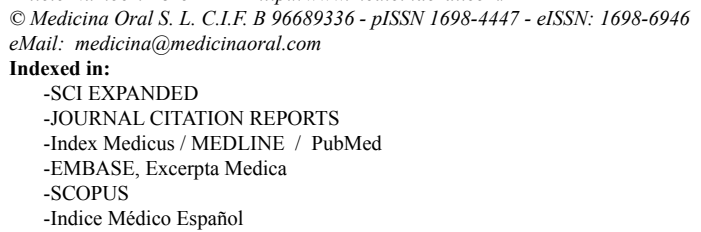

\begin{abstract}
Aim: To evaluate the cytotoxicity of $15 \%$ citric acid, $5 \%$ phosphoric acid and $2.5 \% \mathrm{NaOCl}$ on cultured fibroblasts using MTT colorimetric assay. Methodology: Irrigating solutions of 5\% phosphoric acid, $15 \%$ citric acid, and $2.5 \% \mathrm{NaOCl}$, diluted at $0.1 \%$ and $0.5 \%$, were applied to cell cultures of 3T3L1 fibroblasts. The cell viability was determined by means of MTT colorimetric assay after a period of 1,6 and 24 hours. Percentages of cell viability were analyzed using the Kruskal-Wallis test for global comparisons and the Mann-Whitney U-test for pairwise comparisons. Results: The percentage of cell viability diminished progressively over a 24 hour period in all solutions at both dilutions. At $0.1 \%$ dilution, $2.5 \% \mathrm{NaOCl}(63.39 \%)$ and $15 \%$ citric acid $(53.91 \%)$ showed the highest percentage of cell viability ( $\mathrm{p}=0.083$ ). At $0.5 \%$ dilution, $2.5 \% \mathrm{NaOCl}$ again showed the highest cell viability value (48.51\%). Conclusions: The irrigating solution with the highest percentage of cell viability was $2.5 \% \mathrm{NaOCl}$ at both $0.1 \%$ and $0.5 \%$ dilutions. A very low percentage of cell viability was obtained with $15 \%$ citric acid and $5 \%$ phosphoric acid at $0.5 \%$ dilution.
\end{abstract}

Key words: Citric acid, phosphoric acid, sodium hypochlorite, root canal irrigants, cytotoxicity.

\section{Introduction}

The main objective of endodontic preparation is to clean and disinfect the root-canal system. The use of irrigating solutions for root canal debridement and disinfection may cause their accidental extrusion to the periapex, interfering with the periodontal tissue repair process (1). In both vital and non-vital cases, irrigant can even be extruded in teeth with fully mature, intact apexes. Besides their antiseptic capacity and efficacy to remove the smear layer, the cytotoxic potential of endodontic irrigants should also be analyzed (2).

Irrigation protocols for root canal preparation include the combination of acid or chelating solutions with sodium hypochlorite, applied at different concentrations and during varied time periods $(3,4)$. Sodium hypochlorite $(\mathrm{NaOCl})$ is the most widely used irrigating solution in endodontics, at concentrations of $0.5 \%-5.25 \%$, because of its broad antibacterial spectrum and capacity to dis- 
solve organic matter and necrotic tissue $(5,6)$. At higher concentrations, its solvent and antiseptic properties are greater (7) but so are its toxic effects (8). Studies using MTT colorimetric assay $(9,1)$ reported that the cytotoxicity of different $\mathrm{NaOCl}$ concentrations was lower than that of $17 \%$ EDTA, REDTA, and MTAD (doxycycline, citric acid and Tween 80) solutions.

Acid and chelating irrigating solutions enhance smear layer removal, dentinal wall cleaning, and root canal disinfection (6). Various authors have studied the toxicity of EDTA and citric acid solutions at different concentrations in various cell samples (9-13). Chan et al. (1999) (14) reported a higher death rate of cultured human dental pulp cells with greater acidity of the citric acid solution.

There have been few published studies on the use of phosphoric acid for smear layer removal in endodontics. Some authors $(3,15)$ recommended this agent for root canal preparation at concentrations of $10 \%$ or $32 \%$ in aqueous solution and of $37 \%$ in gel. Recent studies demonstrated that $5 \%$ phosphoric acid in combination with a solution of $2.5 \% \mathrm{NaOCl}$ are effective for smear layer removal during root canal instrumentation (4) and have decalcification capacity on root dentin (16). However, no report could be found on the cytotoxicity of phosphoric acid as an irrigating solution in root canal therapy.

The aim of this study was to compare, using MTT colorimetric assay, the cytotoxicity of $5 \%$ phosphoric acid, $15 \%$ citric acid and $2.5 \% \mathrm{NaOCl}$ in cultured $3 \mathrm{~T} 3$ fibroblasts.

\section{Material and Methods}

\section{Cell Cultures}

The 3T3-L1 fibroblasts (ECACC 86052701) used to test the cytotoxicity of irrigating solutions were obtained from the CIC Culture Collection of the University of Granada (Spain). Cells were placed under sterile conditions in $75 \mathrm{~cm} 2$ flasks that contained $30 \mathrm{ml}$ of culture medium consisting of Dulbecco modified Eagle's medium $($ DMEM $)+2 \mathrm{mM}$ of glutamine $+10 \%$ inactivated fetal bovine serum (PBS). Flasks were kept at $37^{\circ} \mathrm{C}$ in an atmosphere of 5\% CO2 and $95 \%$ humidity until cells reached confluence, when they were removed from the culture medium cells were trypsinized by a 5 -min wash with PBS and EDTA/trypsin solution, followed by removal of this solution and agitation of the flask until cells separated. After trypsinization, specimens were collected by centrifugation at $80-100 \mathrm{~g}$ for $5 \mathrm{~min}$, and cell groups were dispersed in DMEM $+10 \%$ PBS culture medium. Cell suspension was counted under microscope with a Neubauer counting chamber, and cells (1x104) were seeded in 96-well culture plates (Nunc GMBH \& Co. KG, Weisbaden, Germany) with $100 \mu 1$ of culture medium for $48 \mathrm{~h}$ in an oven at $37^{\circ} \mathrm{C}$ in $5 \%$ $\mathrm{CO} 2$ and $95 \%$ humidity atmosphere. Then, a multichannel pipette (Finnipippette, Boeco, Boeckel $+\mathrm{Co}(\mathrm{GmbH}$
+ Co), Hamburg, Germany) was used to remove culture medium from all wells in the plate except for the control wells, adding $10 \mu \mathrm{l}$ of each irrigating solution. Plates were then sealed and placed in an oven at $37^{\circ} \mathrm{C}$ in an atmosphere of 5\% CO2 and $95 \%$ humidity. The assay was performed in quadruplicate in all study groups. Culture plates were always handled in sterile conditions under a Laminar Flow Hood (Nuaire, Fernbrook Lane, Plymouth, $\mathrm{MN}$ ) to avoid bacterial contamination.

Experimental groups

Experimental groups were: (1) control, fresh DMEM culture, (2) DMEM containing 15\% citric acid solution diluted to $0.5 \%, \mathrm{pH} 3.54$ (3) DMEM containing 15\% citric acid solution diluted to $0.1 \%$, pH 7.40 (4) DMEM containing $5 \%$ phosphoric acid solution diluted to $0.5 \%$, pH 2.70 (5) DMEM containing 5\% phosphoric acid solution diluted to $0.1 \%, \mathrm{pH} 6.44$ (6) DMEM containing $2.5 \% \mathrm{NaOCl}$ solution diluted to $0.5 \%, \mathrm{pH} 7.97$ and (7) DMEM containing $2.5 \% \mathrm{NaOCl}$ solution diluted to $0.1 \%, \mathrm{pH} 7.94$.

Cytotoxicity test

Cytotoxicity of irrigating solutions was assessed at 1, 6 , and $24 \mathrm{~h}$ after incubation, evaluating the cell viability by using the MTT colorimetric assay (Roche Diagnostics GMBH, Mannheim, Germany). This assay (17) involves the ability of viable cells to convert a soluble tetrazolium salt, MTT [3-(4.5- dimethylthiazol -2-yl)2-5-diphenylterazolum bromide], into a blue formazan end product by mitochondrial dehydrogenase enzymes. Briefly, $10 \mu \mathrm{l}$ of MTT stock $(5 \mathrm{mg} / \mathrm{ml}$ of MTT in PBS) was added to each culture. After incubation for $4 \mathrm{~h}$ at $37^{\circ} \mathrm{C}$ in an atmosphere of $5 \% \mathrm{CO} 2$ and $95 \%$ humidity, $100 \mu \mathrm{l}$ of $10 \%$ SDS in $0.01 \mathrm{M} \mathrm{HCl}$ was added to each well. The solution was allowed to solubilize overnight in $100 \%$ humidity. The absorbance of each well was determined by using a scanning multiwell spectrophotometer ELISA (Bio-Tek Instruments Inc., VT) at 550nm and was expressed as percentage of the absorbance obtained in the control group.

Statistical analysis

The mean and standard deviation of the percentages of cell viability were calculated for the four dishes. A fullfactorial regression model was used to assess the significance of the interaction among three factors (type of irrigating solution, concentration of irrigating solution, and time of action of irrigating solution) for percentages of cell viability. The Kolmogorov-Smirnov test was used to assess the distribution of the data. Because results for each group did not follow a normal distribution, variables were analyzed using a non-parametric test. The percentages of cell viability from different irrigating solutions were analyzed using the Mann-Whitney U-test (pairwise comparisons) and the Kruskal-Wallis test (global comparisons). The level of statistical significance was set at $\mathrm{p}<05$. 


\section{Results}

Full-factorial regression analysis of the influence of the type of irrigating solution ( $15 \%$ citric acid, $5 \%$ phosphoric acid, or $2.5 \% \mathrm{NaOCl}$ ), concentration of irrigating solution $(0.1$ or $0.5 \%)$ and time of action of irrigating solution $(1,6$, or $24 \mathrm{~h})$ revealed a statistically significant interaction among these three factors in the percentages of cell viability $(\mathrm{p}<0.001)$ (Tablel).

At dilutions of the solutions up to $0.1 \%$ (Figure 1), the percentage of cell viability progressively diminished $1 \mathrm{~h}$ to $6 \mathrm{~h}$ and from $6 \mathrm{~h}$ to $24 \mathrm{~h}$, with significant global differences among $15 \%$ citric acid $(\mathrm{p}=0.010), 5 \%$ phosphoric acid $(\mathrm{p}=0.007)$, and $2.5 \% \mathrm{NaOCl}(\mathrm{p}=0.012)$. The highest percentage of cell viability at 24 hours was obtained with $2.5 \% \mathrm{NaOCl}(63.39 \%)$ followed by $15 \%$ citric acid (53.91\%), with no significant differences between them $(p=0.083)$. The lowest percentage cell viability was ob- served with 5\% phosphoric acid (6.91\%), exhibited significant differences with other solutions $(\mathrm{p}=0.021)$. Remaining comparisons among irrigating solutions were also significant.

At $0.5 \%$ dilution of irrigating solutions (Figure 2), the percentage of viable cells progressively reduced up to $24 \mathrm{~h}$ in cell cultures with $2.5 \% \mathrm{NaOCl}(48.51 \%)$, showing significant differences among time points $(\mathrm{p}=0.010)$, while the lowest percentage cell viability at all three time points was observed with $15 \%$ citric acid and 5\% phosphoric acid, with significant differences between three time points ( $p=0.015$ and $p=0.020$, respectively). All comparisons among irrigating solutions showed significant differences, except for the comparison between $15 \%$ citric acid and $5 \%$ phosphoric at $1 \mathrm{~h}(\mathrm{p}=0.215), 6 \mathrm{~h}$ $(\mathrm{p}=1.0)$ and $24 \mathrm{~h}(\mathrm{p}=0.127)$.

Table 1. Cell viability: influence of the time and the concentration of the irrigating solutions

\begin{tabular}{|l|c|r|l|l|r|l|l|r|l|l|}
\hline & & \multicolumn{3}{|c|}{1 hour } & \multicolumn{3}{c|}{6 hours } & \multicolumn{3}{c|}{24 hours } \\
\hline Control & & 98.99 & \pm & $1.87^{1}$ & 99.20 & \pm & $0.63^{2}$ & 93.48 & \pm & $3.80^{1,2}$ \\
\hline \multirow{2}{*}{$\begin{array}{l}15 \% \text { citric } \\
\text { acid }\end{array}$} & {$[0,1]$} & 78.04 & \pm & $4.13^{\mathrm{a}, 1,2}$ & 62.75 & \pm & $2.16^{\mathrm{b}, 1,3}$ & 53.91 & \pm & $4.77^{\mathrm{b}, 2,3}$ \\
\cline { 2 - 12 } & {$[0,5]$} & 1.20 & \pm & $0.32^{\mathrm{a}, 1}$ & 1.46 & \pm & $0.00^{\mathrm{b}, 2}$ & 1.80 & \pm & $0.19^{\mathrm{b}, 1,2}$ \\
\hline \multirow{2}{*}{$\begin{array}{l}5 \% \text { phospho- } \\
\text { ric acid }\end{array}$} & {$[0,1]$} & 31.48 & \pm & $2.36^{\mathrm{b}, 1,2}$ & 14.71 & \pm & $3.85^{\mathrm{c}, 1,3}$ & 6.91 & \pm & $0.92^{\mathrm{c}, 2,3}$ \\
\cline { 2 - 12 } & {$[0,5]$} & 1.01 & \pm & $0.00^{\mathrm{b}, 1,2}$ & 1.46 & \pm & $0.30^{\mathrm{c}, 1}$ & 1.47 & \pm & $0.33^{\mathrm{c}, 2}$ \\
\hline \multirow{2}{*}{\begin{tabular}{l}
$2.5 \% \mathrm{NaOCl}$ \\
\cline { 2 - 12 }
\end{tabular}} & {$[0,1]$} & 97.78 & \pm & $1.27^{1,2}$ & 70.11 & \pm & $6.94^{\mathrm{d}, 1}$ & 63.39 & \pm & $4.63^{\mathrm{d}, 2}$ \\
\cline { 2 - 11 } & {$[0,5]$} & 95.73 & \pm & $2.01^{1,2}$ & 54.03 & \pm & $3.49^{\mathrm{d}, 1,3}$ & 48.51 & \pm & $2.93^{\mathrm{d}, 2,3}$ \\
\hline
\end{tabular}

* In the full-factorial regression model, $\mathrm{p}$ values was $<.001$ (for irrigating solution $\mathrm{x}$ concentration solution $\mathrm{x}$ time interaction).

Read vertically, the same letters indicate significant differences between the two concentrations of the same solution.

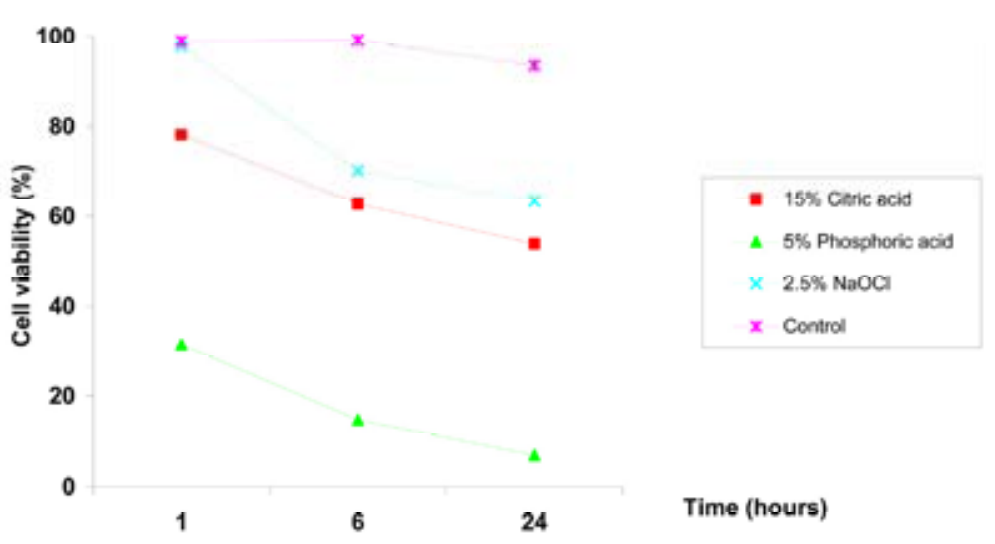

Fig. 1. Viability curves of 3T3L1 cells treated with different irrigating solutions diluted up to $0.1 \%$ and control. All cultures showed progressive diminution of the percentage of cell viability. Cell cultures treated with $5 \%$ phosphoric acid exhibited significant lower percentage de viable cells than the other groups $(\mathrm{p}<0.05)$. 


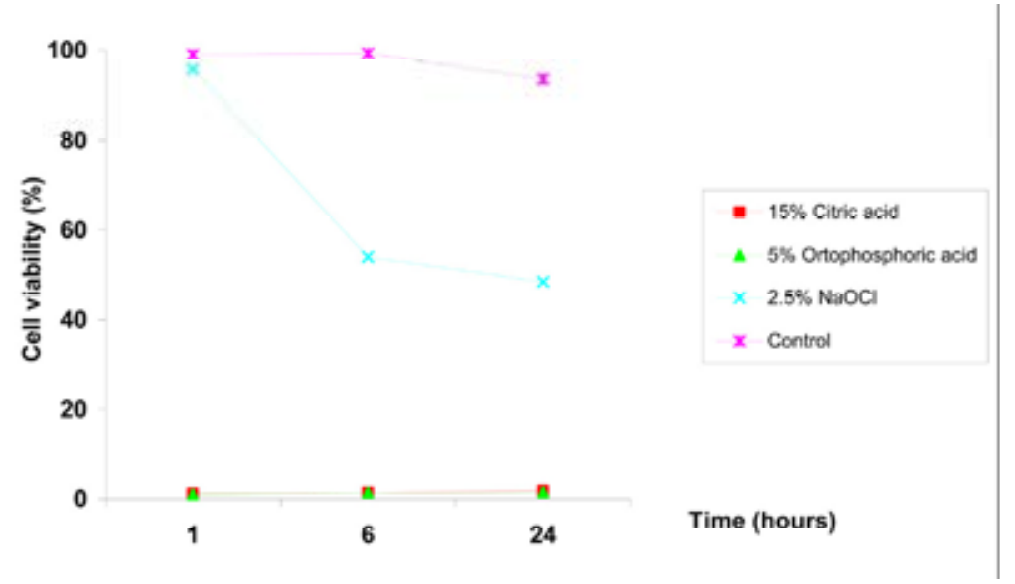

Fig. 2. Viability curves of 3T3L1 cells treated with different irrigating solutions diluted up to $0.5 \%$ and control. The cultures treated with $2.5 \% \mathrm{NaOCl}$ showed progressive diminution of the percentage of cell viability. The $15 \%$ citric acid and $5 \%$ phosphoric acid exhibited the lowest percentage of the cell viability $(\mathrm{p}<0.05)$.

\section{Discussion}

Irrigating solutions should not only be assessed as antibacterial or chelating agents but the biological repercussion of their accidental extrusion on host tissue should also be considered (1). Thus, an ideal irrigant would be one that combined a maximum antibacterial and solvent effect on organic and inorganic tissue, with minimal toxic effect on periapical tissue.

The MTT tetrazolium assay is considered a sensitive index to evaluate the cytotoxicity of dental materials (17) and has been used by several authors $(1,9,13,14)$. Its main advantages are the rapidity and accuracy of the technique, its reproducibility, and the fact that no radioisotopes are used. A further benefit is that it does not need a washing step, which could cause variations in the sample (17).

In the present study all the irrigating solutions applied on the fibroblasts cultured were diluted to $0.5 \%$ or $0.1 \%$, because cultured cells are more susceptible than periapical tissue to the toxic effects of drugs (11). In the body, the phagocytic cells and the lymph and blood channels all help to dilute and carry away the drug. It would be expected that the drugs would not be so irritating in the clinical situation as in the cytotoxicity studies (18).

Our results showed that $0.1 \%$ and $0.5 \%$ dilutions of $2.5 \%$ $\mathrm{NaOCl}$ solution were less cytotoxic on 3T3-L1 cells compared with $0.1 \%$ and $0.5 \%$ dilutions of $15 \%$ citric acid and 5\% phosphoric acid solutions, consistent with other reports that compared the cytotoxicity of $\mathrm{NaOCl}$ with EDTA (9), REDTA, and MTAD (1) solutions by using the MTT colorimetric assay. However, Hidalgo et al. (2) using an XTT assay, observed cell death in cultured skin fibroblasts after application of $\mathrm{NaOCl}$ at concentrations $>0.05 \%$ for $2-24 \mathrm{~h}$. Furthermore, Chang et al.
(19), using a PI fluorescence assay, found that $0.4 \%$ and $0.2 \%$ dilutions of a $5.25 \% \mathrm{NaOCl}$ solution killed human periodontal ligament cells after 3 and $24 \mathrm{~h}$ of exposure, respectively. Discrepancies with the present results may be due to the use of different cell lines, procedures, and experimental conditions used to assess cytotoxicity. The cytotoxicity of acid solutions (15\% citric acid, $5 \%$ phosphoric acid) was lower at $0.1 \%$ dilution than at $0.5 \%$ dilution, at which the cell viability percentage was virtually zero for both solutions. Thus, in the case of $15 \%$ citric acid diluted at $0.1 \%$, the cell viability percentage was above $50 \%$ at each time point, whereas virtually no cells were viable at any time point after exposure to the same solution at $0.5 \%$ dilution. Malheiros et al. (11) found higher NIH 3T3 fibroblast viability at $24 \mathrm{~h}$ with an $0.5 \%$ dilution of $15 \%$ citric acid compared with an $0.5 \%$ dilution of $17 \%$ EDTA solution and Scelza et al. (10) also reported higher cell viability and survival with a $10 \%$ citric acid solution than with $1 \%, 0.1 \%$ and $0.01 \%$ dilutions of an EDTA-T solution. Nevertheless, none of these studies reported the $\mathrm{pH}$ of the irrigating solutions used and the cell viability was determinate using the Trypan blue dye exclusion assay. However, Chan et al. (14) demonstrated, using MTT assay, which citric acid cytotoxicity depends on the solution $\mathrm{pH}$. Thus, citric acid concentrations at $0.1 \%(\mathrm{pH} 7.20), 0.25 \%(\mathrm{pH}$ 6.22 ), and $0.50 \%(\mathrm{pH} 4.74)$ reduced cell survival by $20 \%, 74 \%$ and $98 \%$, respectively, in comparison with a control group. These findings appear to indicate that the $\mathrm{pH}$ of acid irrigating solutions decreased the $\mathrm{pH}$ of the culture medium, causing a significant reduction in cell viability.

In the present study, the mean $\mathrm{pH}$ of the $15 \%$ citric acid solution decreased from 7.40 for the $0.1 \%$ dilution to 
3.54 for the $0.5 \%$ dilution. The worst cell viability results were obtained with $5 \%$ phosphoric acid at both dilutions studied, and these cytotoxicity results were also related to the $\mathrm{pH}$ of the solution $(\mathrm{pH}=6.44$ for a $0.1 \%$ dilution and $\mathrm{pH}=2.70$ for a $0.5 \%$ dilution). In this context, Goldman et al. (20) reported that cell death was caused by the effect of extracellular acidosis on neurons and glial cells after $10 \mathrm{~min}$ of exposure to a lactic acid solution with $\mathrm{pH}$ of 3.8-4.2, with no cells surviving after $1 \mathrm{~h}$ of exposure at a $\mathrm{pH}$ of 5.2 .

Irrigation protocols for root canal preparation include the combination of acid or chelating solutions with sodium hypochlorite, applied at different concentrations and during varied time periods $(3,4)$. The choice of an irrigating solution is based on its chemical, physical and biological properties and their accidental extrusion into the periapical area should also be considered.

In this in vitro study all irrigants tested showed moderate to severe cytotoxicy in a concentration-dependent manner. The highest percentage of cell viability was obtained with $0.1 \%$ and $0.5 \%$ dilutions of $2.5 \% \mathrm{NaOCl}$. Very low percentages of cell viability were obtained with $0.5 \%$ dilutions of $5 \%$ phosphoric acid or $15 \%$ citric acid.

\section{References}

1. Zhang W, Torabinejad M, Li Y. Evaluation of cytotoxicity of MTAD using the MTT-tetrazolium method. J Endod. 2003;29:654-7.

2. Hidalgo E, Bartolome R, Dominguez C. Cytotoxicity mechanisms of sodium hypochlorite in cultured human dermal fibroblasts and its bactericidal effectiveness. Chem Biol Interact. 2002;139:265-82.

3. Garberoglio R, Becce C. Smear layer removal by root canal irrigants. A comparative scanning electron microscopic study. Oral Surg Oral Med Oral Pathol. 1994;78:359-67.

4. Pérez-Heredia M, Ferrer-Luque CM, González-Rodríguez MP. The effectiveness of different acid irrigating solutions in root canal cleaning after hand and rotary instrumentation. J Endod. 2006;32:993-7.

5. Siqueira JF Jr, Rôças IN, Favieri A, Lima KC. Chemomechanical reduction of the bacterial population in the root canal after instrumentation and irrigation with $1 \%, 2.5 \%$, and $5.25 \%$ sodium hypochlorite. J Endod. 2000;26:331-4.

6. Zehnder M. Root canal irrigants. J Endod. 2006;32:389-98.

7. Carson KR, Goodell GG, McClanahan SB. Comparison of the antimicrobial activity of six irrigants on primary endodontic pathogens. J Endod. 2005;31:471-3.

8. Pashley EL, Birdsong NL, Bowman K, Pashley DH. Cytotoxic effects of $\mathrm{NaOCl}$ on vital tissue. J Endod. 1985;11:525-8.

9. Serper A, Calt S, Dogan AL, Guc D, Ozçelik B, Kuraner T. Comparison of the cytotoxic effects and smear layer removing capacity of oxidative potential water, $\mathrm{NaOCl}$ and EDTA. J Oral Sci. 2001;43:233-8.

10. Scelza MF, Antoniazzi JH, Scelza P. Efficacy of final irrigation--a scanning electron microscopic evaluation. J Endod. 2000;26:355-8.

11. Malheiros CF, Marques MM, Gavini G. In vitro evaluation of the cytotoxic effects of acid solutions used as canal irrigants. J Endod. 2005;31:746-8.

12. Sousa SM, Bramante CM, Taga EM. Biocompatibility of EDTA, EGTA and citric acid. Braz Dent J. 2005;16:3-8.

13. Amaral KF, Rogero MM, Fock RA, Borelli P, Gavini G. Cytotoxicity analysis of EDTA and citric acid applied on murine resident macrophages culture. Int Endod J. 2007;40:338-43.

14. Chan CP, Jeng JH, Hsieh CC, Lin CL, Lei D, Chang MC. Morphological alterations associated with the cytotoxic and cytostatic effects of citric acid on cultured human dental pulp cells. J Endod. 1999;25:354-8.

15. Ayad MF. Effects of rotary instrumentation and different etchants on removal of smear layer on human dentin. J Prosthet Dent. 2001;85:67-72.

16. Pérez-Heredia M, Ferrer-Luque CM, González-Rodríguez MP, Martín-Peinado FJ, González-López S. Decalcifying effect of $15 \%$ EDTA, $15 \%$ citric acid, $5 \%$ phosphoric acid and $2.5 \%$ sodium hypochlorite on root canal dentine. Int Endod J. 2008;41:418-23.

17. Mosmann T. Rapid colorimetric assay for cellular growth and survival: application to proliferation and cytotoxicity assays. J Immunol Methods. 1983;65:55-63.

18. Wall GL, Dowson J, Shipman C Jr. Antibacterial efficacy and cytotoxicity of three endodontic drugs. Oral Surg Oral Med Oral Pathol. 1972;33:230-41.

19. Chang YC, Huang FM, Tai KW, Chou MY. The effect of sodium hypochlorite and chlorhexidine on cultured human periodontal ligament cells. Oral Surg Oral Med Oral Pathol Oral Radiol Endod. 2001;92:446-50.

20. Goldman SA, Pulsinelli WA, Clarke WY, Kraig RP, Plum F. The effects of extracellular acidosis on neurons and glia in vitro. J Cereb Blood Flow Metab. 1989;9:471-7.

\section{Acknowledgments}

The authors wish to express their gratitude to Dr. María del Carmen Ramírez Tortosa and Dr. Nieves Rodríguez Cabezas for their technical assistance. 